\section{On the need for an ecologically dimensioned medical humanities}

\author{
Jonathan Coope
}

\begin{abstract}
Increasing calls from medical professionals and scholars suggest an urgent need for better and more widespread understandings of the ecological dimensions of health. Such calls have included: two recent Lancet special commissions on impacts of climate change on health; and recognition by senior figures from the WHO and United Nations of relationships between human impacts on the natural world and disease pandemics, with some suggesting prevention of future pandemics may require a radical reassessment of modernity's relationship with the natural world. Among the medical humanities as a whole, however, calls for better and more widespread understandings of the ecological dimensions of health have not always been as prominent, or urgently expressed, as they might be.

This paper, which presumes there is an urgent need for better and more widespread understandings of the ecological dimensions of human health, draws on ecological public health and other models to propose an ecological re-visioning of our conceptions of health and medical humanities; and in ways that challenge some contemporary assumptions about health, well-being and the 'good society'. Indeed, once we begin to heed what ecocritic Tim Morton terms 'the ecological thought', we may discover few areas of healthcare and the humanities remain untouched by its implications.

With growing recognition that the fate of global human health and the fate of the biosphere are inextricably entwined, the project of a more ecologically dimensioned medical humanities appears both timely and urgent. Such a project may represent a significant opportunity for the medical humanities, and a significant responsibility.
\end{abstract}

\section{INTRODUCTION}

Increasing calls from medical professionals and scholars suggest an urgent need for better and more widespread understandings of the ecological dimensions of health-among healthcare practitioners and scholars, and among the wider public as well. Such calls have included:

Mary Seacole Research Centre, De Montfort University City Campus, Leicester, UK

Correspondence to Dr Jonathan Coope, Mary Seacole Research Centre, De Montfort University, Leicester LE1 9BH, UK; jcoope@dmu.ac.uk two Lancet special commissions-in 2009 and 2015-on the impacts of anthropogenic climate change on human health ${ }^{1}$ and support by some medics for the environmental movement Extinction Rebellion. ${ }^{2}$ Meanwhile, senior figures from the United Nations and WHO have drawn attention to relationships between human impacts on the natural world and human disease pandemics, suggesting that 'Coronavirus is a warning to us to mend our broken relationship with nature'. ${ }^{3}$ These calls and others remind us that any efforts which conceptualise or compartmentalise health and healthcare apart from, or away from, their ecological contexts are increasingly implausible.

Such compartmentalisation nevertheless remains a commonplace problem in medicine according to David Pencheon, founder and former director of the NHS's Sustainable Development Unit. For Pencheon, addressing such problems 'is about framing' and 'changing the narrative' of our conceptualisations of healthcare. ${ }^{4}$

Now, reframing healthcare narratives ecologically, while critiquing narratives that compartmentalise medicine apart from its ecological contexts, may offer a significant opportunity for the medical humanities, and a significant responsibility. But despite previous calls for more ecological awareness in medical humanities (eg, Brandy Schillace's suggestion that climate change is among the signature global health issues of our time; $;^{5}$ the 2017 Harvard University conference on 'Medical Humanities, Social Sciences, and the Environment'; Greg Mittman's work on interactions between medical history and environmental history), calls for better and more widespread understandings of the ecological dimensions of health have not always been as prominent, or urgently expressed, as they might be among the medical humanities as a whole. For example, a search within Medical Humanities (among the foremost journals in the field) for articles which include 'ecology', 'environment', 'climate change', or 'ecocrisis' in their title yielded only one 'hit'. And that article, on closer inspection, refers only to a technological environment-that is, to an 'artistically designed multisensory environment'-rather than a natural environment. ${ }^{6}$
This paper presumes there is an urgent need for better and more widespread understandings of the ecological dimensions of health and draws on my own experiences of, among other things: teaching on two postgraduate sustainability programmes, teaching on a Medical Leadership, Education and Research postgraduate programme to medical doctors and research in health humanities funded by the Medical Research Council (MRC), Global Challenges Research Fund (GCRF) and Arts and Humanities Research Council (AHRC). The paper begins by outlining three areas in which 'green' thinking is beginning to have significant impact on healthcare understandings. It then explores how some commentators are changing the way they frame their stories about humankind's relations with the natural world by suggesting ecological crisis need not be read only as a potential global health crisis, but that it might also be considered as a health opportunity. Finally, the paper explores how an ecologically informed medical humanities might challenge some of modernity's more cherished assumptions about nature, science and reality.

With growing recognition that the fate of global human health and the fate of the biosphere are inextricably entwined, the project of a more ecologically dimensioned medical humanities appears both timely and urgent.

\section{THREE AREAS OF PROGRESS TOWARDS ECOLOGICAL THINKING IN HEALTHCARE}

\section{Systems understandings}

Atul Gawande suggests healthcare is now graduating 'from the century of the molecule to the century of the system'; and that after a period when western medicine's highest hopes tended to focus on reducing problems to their smallest components-such as molecules, genes, and neurons-system complexities are increasingly recognised at most every level of healthcare, from the immune system to quality improvement in healthcare delivery. ${ }^{7}$ Systems thinking reminds us that the relationships between elements in a system can be as important as the elements themselves, and that a complex system cannot be fully understood by analysis of its constituent elements alone. Thus, the relevance of so-called emergent properties (properties of complex systems that cannot be deduced from reductionist analysis of system elements) is increasingly recognised in healthcare and its subfields. 
The importance of systems thinking to an ecologically dimensioned healthcare lies in its ability to help us understand ways in which systems of health and healthcare are embedded within larger systems: the Earth's ecosystems and biosphere on which all terrestrial life depends. The One Health movement, among others, has drawn attention to this dependency as it seeks to prevent and mitigate problems which arise 'between humans ... and their various environments' ${ }^{8}$

But systems thinking is not always easy. It may, for instance, require considerable expansion of the 'boundaries of time and space' within which any particular issue is conceptualised. ${ }^{9}$ Overuse of antibiotics is one example of how unintended consequences can arise when we fail to consider the longer-term implications of actions or policies.

\section{Ecological public health}

According to Tim Lang and Geof Rayner of the ecological public health movement, four broad overlapping models have dominated the ways in which public health has been conceptualised hitherto: (1) The sanitary-environmental model, pioneered in the nineteenth century by Edwin Chadwick and others, which focused on the health of populations in their physical environments; (2) Biomedical models; (3) Sociobehavioural approaches, focusing on social marketing and 'nudge' approaches to altering behaviours; and (4) Technoeconomic approaches which focus on economic growth and technoscientific innovation as key to improving public health.

According to Lang and Rayner, what we now need is a new model: an ecological public health informed by ecological systems thinking. This new model

draws upon and integrates parts of the other models. Secondly, it articulates modern thinking about complexity and system dynamics, addressing, for example, questions of non-linearity, variations in scale, feedback, and other emergent qualities of nature, biology and human behaviour ... Thirdly, ecological public health seeks to build knowledge as a continual intellectual engagement. This means more than just evidence, and includes the open pursuit of social values, highlighting the role of interest groups, and debate across society not just within restricted scientific circles. Think Darwin and Wallace, Beveridge or Roosevelt: big thinking about the nature of life, good societies, order and change ... Fifthly, this is an overtly interdisciplinary and multiactor model. It celebrates that public health requires action on multiple fronts and em- braces the argument familiar in the 19th century that public health action requires a public health movement. ${ }^{10}$

The ecological public health model thus reminds us of the inadequacy of relying on evidence-based medicine alone. Instead, it requires a multidisciplinary and historically informed approach that acknowledges the need for a broader societal vision of human flourishing-_big thinking about the nature of life, good societies, order and change'.

\section{Ecological mental health}

With mental health disorders arguably responsible for 'the largest proportion of the global burden of disease ${ }^{11}$ some commentators are beginning to suggest that our relationships with non-human nature may have profound implications for our mental health. Craig Chalquist, in reviewing the empirical literature on 'nature connectedness' approaches to mental health, concludes that:

1. Disconnection from the natural world ... produces a variety of psychological symptoms that include anxiety, frustration, and depression ...

2. Reconnection to the natural world whether through gardens, animals, nature walks outside, or nature brought indoors - not only alleviates these symptoms, but also brings a larger capacity for health, self-esteem, selfrelatedness, social connection, and joy.

3. Reconnection also works across treatment modalities to replace a pathological sense of inner deadness or alienation from self, others and world with a rekindling of inner aliveness and enjoyment of relatedness to self, others, and world. ${ }^{12}$

In addition to the growing number of empirical studies into mental health impacts of human relations with nature, some ecopsychologists argue that the commonplace presumption that mind 'In Here' and nature 'Out there' are, or ever were, separate realms has been an illusion, a cultural construction-although a remarkably persistent one in western culture. $^{13}$

\section{REFRAMING ECOCRISIS AS A HEALTHCARE OPPORTUNITY}

When considering the implications of climate change and the despoliation of the natural world, it can be difficult to avoid a feeling or tone of apprehension, with recent reports from the IPCC, for instance, suggesting there may only be 12 years for humankind to undertake the significant societal transformations necessary to forestall the worst effects (including health effects) of runaway climate change. ${ }^{14}$

But terrifying people with predictions of dire ecological catastrophe may not be the most effective strategy available to us for motivating people to adopt more 'pro-environmental' behaviours. According to Solitaire Townsend, for example, medics and psychotherapists have long known that helping people to 'imagine a better future is more effective than scare tactics'. Townsend is among those who point to the plethora of evidence which indicates simply giving people the 'facts' or 'disaster narrative' about environmental problems does not work-if by 'work' we mean persuading people to adopt more environmentally sustainable lifestyles and behaviours. Townsend: 'It should work that telling 'facts' about climate change would change behaviour, but it doesn't. We need to tell a different story'. ${ }^{15}$ Consequently, it may now be a matter of some urgency that we develop narratives which can help people 'imagine a better future', one that is more ecologically wholesome.

Partly in a bid to offer people just such a positive vision-of the health and well-being benefits of tackling environmental problems such as climate change-the Lancet, in their climate change report of 2015 sought to narrativise the more immediate health co-benefits that can emerge from policies which seek to address environmental problems. As Anthony Costello, co-chair of the 2015 Lancet Commission on Health and Climate Change put it,

All the things we want to do to combat climate change will also protect us against ill health ... We want to shift the balance from talk of catastrophes to a 'we-can-fix-this' mentality. ${ }^{16}$

Thus, whereas the earlier 2009 Lancet report on climate change found climate change to be 'the biggest global health threat of the $21^{\text {st }}$ century', the central finding of the 2015 report is that

tackling climate change could be the greatest global health opportunity of the $21^{\text {st }}$ century ... [g]iven the potential of climate change to reverse the health gains from economic development, and the health co-benefits that accrue from actions for a sustainable economy... ${ }^{17}$

Some of these health co-benefits include: improved diet (eg, reducing red meat 
consumption reduces $\mathrm{CO}_{2}$ emissions and is better for health), improved air quality from reduced burning of fossil fuels and driving less (can reduce $\mathrm{CO}_{2}$ emissions while increasing physical exercise).

But as David Pencheon indicates in discussion with Transition movement founder Rob Hopkins, environmental sustainability may have even more radical-and positive-implications for the ways we conceive of health, care, human flourishing and our visions for what constitutes the 'good society':

We need to think and talk and conceptualise health in a different way than we've normally done. Not just living without mental illness or physical illness but living truly fulfilling, meaningful, connected lives, depends on roughly four things if you put things like genes aside:

- Do you have a house, do you have somewhere to live?

- Do you have a job, are you in education or do you have a fulfilling role in your community?

- Are you connected socially, do you have friends, do you have a community you're part of?

- Do you have access to services, which are the icing on the cake for health which deliver things which none of the first three can do?

That's about social care, it's about healthcare, it's about welfare. It includes culture and libraries and all those other things that make life worth living. If you take that as your concept of public health or community health or holistic health or health in the broader sense, then it's absolutely clear that public health is by far the best investment we could make in local, meaningful, resilient, sustainable communities where it is just a much better place to live. ${ }^{18}$

What sustainable healthcare thinkers such as Pencheon are suggesting, in other words, is that an ecologically viable future and a 'greening' of healthcare need not be conceived as a privation, as a lessening of health opportunities. Instead, a 'greening' of healthcare might be conceived more properly as a positive vision: of an ecologically viable future, that is more humane and convivial as well.

\section{TO WHAT EXTENT MIGHT AN ECOLOGICALLY DIMENSIONED MEDICAL HUMANITIES CHALLENGE COMMONPLACE ASSUMPTIONS OF MODERNITY?}

If environmental problems are an urgent threat to global health, and ecological thinking a potential source of health co-benefits, why do healthcare issues so often continue to be compartmentalised and conceptualised apart from and away from their ecological contexts? According to Pencheon, one of the central challenges confronting a more ecological approach to healthcare is that

we're so addicted to what we currently know, that we don't have the vision to see that it could be much better. It could be so much better for the present and for the future. Sometimes we do lack vision and we do lack courage. Things do not have to be this way and to live sustainable lives we don't have to resort to living in caves. ${ }^{19}$

According to many ecological thinkers, the task of unpicking that burden of 'what we currently know' is a profound one, which may require challenges to some of modernity's most cherished assumptions. Indeed, once we pay serious attention to what ecological cultural theorist Tim Morton terms 'the ecological thought' we may find few aspects of our lives remain untouched. ${ }^{20}$

For example, while historians of medicine have traced the role of the mechanical philosophy in leading to a mechanical or biomechanical understanding of the body and self, 'green' authors such as ecofeminist Charlene Spretnak press the critique of science further to suggest that the same cultural influences which led to the increasing mechanisation of our human selfunderstanding also led to the degradation of our sensuous understandings of, and responses to, the natural world. ${ }^{21}$ Putting this argument in its starkest terms: psychologists remind us that, often, a necessary precursor to an act of rape against another person is that the perpetrator (usually male) objectify their victim first. By 'objectify', we mean rendering the victim an $i t$ : by the psychological act of withdrawing sympathy and denying value, autonomy and dignity to the victim. Now, when someone objectifies a person in this way, we understandably feel horror. But when we objectify non-human nature in this way-as the widely accepted scientific picture of nature and reality has done for much of the past 300 yearsmany of us no longer even flinch. We call it 'rape' when we objectify a person; but when we objectify nature, we call it science. As historian and ecopsychologist Ted Roszak puts it: 'At the psychological level, rape stems from a distinct state of mind that is the same whether the victim is a woman or a rainforest'. ${ }^{22}$ And as a cultural force, science has been among the most pervasive influences in Western, and increasingly globalised, modernity. Many environmental thinkers, perceive this alienative psychology - which estranges us from felt and sympathetic relationship with more-than-human nature-as among the fundamental roots of modernity's environmental predicaments. Moreover, they suggest the portrait of reality that much of modern science has provided us with-in its earlier Newtonian and Cartesian phases, and in many more recent quantum and postmodern phases-has only served to invite and deepen that experiential estrangement from the natural world. Indeed, even among contemporary environmental humanities, we still commonly find conceptions of knowledge of the natural world that are no less psychologically underdimensioned. ${ }^{23}$

Politics of ecology has often overlapped with the politics of feminism, since both have perceived the patriarchal, and commonly masculinist, aspects of objectification. ${ }^{24}$ Such ecological politics also finds common cause with much Indigenous and post-development scholarship—not least because the ecologically destructive aspects of modernity appear all too obvious to those Indigenous and other scholars for whom animist reciprocity with the natural world may still remain a vividly experienced reality. ${ }^{25}$

Wade Pickren in Psychology and Health: Culture, Place, History insists Western modernity needs to learn from non-modern and Indigenous cultures in order to cultivate a new psychology of health that might help us 'through our growing climate crisis and its sequelae to a better, more humane society, where our oneness with the earth is positive for the earth as well as for humans. ${ }^{26}$ Jay Griffiths similarly suggests that, when it comes to environmental awareness, we need a change of heart... a metanoia. And the humanities, including the arts and an earth-embracing cultural theory, have a crucial role to play in that:

we need a change ... which involves culture going ... 'down' to its roots, profound in the deep earth, in the root of the word cultus: nurturing care and respect, and offering truths to humanity. In its evidence and reliable data, science offers its truths, but from art we need truths of a different order: ... parables to embody it and ethics to sustain the implementation of that knowledge. It is through stooping that art conquers, Lear on the heath, finding his common humanity on the common ground. This is the profound task of art, to find seeds of transcendence deep in the dark and minding earth. ${ }^{27}$ 
If Griffiths is right, then an ecologically dimensioned healthcare need not be solely a matter of privation, belttightening or simply less. For once we begin to expand our conceptions of 'care' towards convivial fellowship with the other-than-human beings with whom we share our destiny on the earth, maybe we will make a happy discovery that, in so doing, we also expand the compass of our lived experience ... of wealth, wellbeing and what it might mean to be fully human.

Funding The authors have not declared a specific grant for this research from any funding agency in the public, commercial or not-for-profit sectors.

Competing interests None declared.

Patient consent for publication Not required.

Provenance and peer review Not commissioned; externally peer reviewed.

(c) Author(s) (or their employer(s)) 2021. No commercial re-use. See rights and permissions. Published by BMJ.

\section{Check for updates}

To cite Coope J. Med Humanit 2021;47:123-127.

Accepted 10 September 2020

Published Online First 4 December 2020

Med Humanit 2021;47:123-127. doi:10.1136/ medhum-2019-011720

\section{ORCID iD}

Jonathan Coope http://orcid.org/0000-0001-72843814

\section{NOTES}

1. Anthony Costello et al. (2009). "Managing the health effects of climate change: lancet and University College London Institute for Global Health Commission." The Lancet 373, no. 9676 (2009): 1693-1733; Nick Watts et al. (2015). "Health and climate change: policy responses to protect public health." The Lancet 386, no 10006 (2015): 1861-914.

2. Underwood (2019). "Doctors against climate catastrophe." The Guardian, Letters, June 27, 2019.

3. Lambertini, Mrema, and Neira (2020). "Coronavirus is a warning to us to mend our broken relationship with nature." The Guardian, June 17, 2020, accessed, August 25, 2020, https://www.theguardian.com/ commentisfree/2020/jun/17/coronavirus-warningbroken-relationship-nature.

4. "Making the health system more sustainable - Q\&A with David Pencheon OBE" YouTube, accessed August 22, 2020, https://www.youtube.com/watch?v=h_ AJuGC-7al.

5. Brandy Schillace. "Editor's note: global outreach." Medical Humanities 44, no.1 (2018): 217.

6. Bliss Cavanagh et al. (2019). "It's like another world: the perceived beneficial effects of an artistically designed multisensory environment." Medical humanities 45, no. 1 (2019): 52-59.

7. Gawande (2014). "The Century of the System." $B B C$ Reith Lectures. BBC Radio 4, December 6, 2014. Lecture; Paul E Plsek and Trisha Greenhalgh (2001). "The challenge of complexity in health care." BMJ 323, no. 7313 (2001): 625-28; Boaden et al. (2008). Quality improvement: theory and practice in healthcare. NHS Institute for Innovation and Improvement, 2008.

8. "One Health Global Network. What is One Health?" One Health Global Network, accessed May 30, 2019, http://www.onehealthglobal.net/what-is-one-health.

9. "The Value of Systems Thinking," Center for Disease Control and Prevention (CDC), accessed May 30, 2019, https://www.youtube.com/watch?v=Fo3ndxVOZEO.

10. Tim Lang and Geof Rayner (2012). "Ecological public health: the 21st century's big idea? An essay by Tim Lang and Geof Rayner." BMJ 345, no. (2012): e5466: 17-20.

11. Wainberg, Milton L., Pamela Scorza, James M. Shultz, Liat Helpman, Jennifer J. Mootz, Karen A. Johnson, Yuval Neria, Jean-Marie E. Bradford, Maria A. Oquendo, and Melissa R. Arbuckle. "Challenges and opportunities in global mental health: a research-to-practice perspective." Current psychiatry reports 19, no. 5 (2017): 28.

12. Craig Chalquist (2009). "A look at the ecotherapy research evidence." Ecopsychology 1, no. 2 (2009): 70.

13. Theodore Roszak (1992). The Voice of the Earth. (New York, NY: Simon \& Schuster, 1992), 44-47.

14. IPCC (2018). "Special Report: Global Warming of 1.5 ${ }^{\circ} \mathrm{C}$, " IPCC, 2018, https://www.ipcc.ch/sr15/

15. Townsend (2019). "Making sustainability so desirable it becomes normal." Seminar, De Montfort University, April 4, 2019.

16. Anthony Costello et al. (2009), cited in Andy Coghlan (2015), "Fighting climate change is opportunity to improve public health." New Scientist, 3027, 23 June, 2015, accessed, May 28, 2019, https://www. newscientist.com/article/mg22630273-900-fightingclimate-change-is-opportunity-to-improve-publichealth/.

17. Nick Watts et al. (2015). "Health and climate change: policy responses to protect public health." The Lancet 386, no. 10006 (2015): 1861-914.

18. David Pencheon, interviewed in Rob Hopkins, "Meet the man bringing Transition to the NHS." Transition Network, June 2, 2014, https://transitionnetwork.org/ news-and-blog/meet-the-man-bringing-transitionto-the-nhs; see also James N Smith, Rob Hopkins, and David Pencheon (2017). "Could the Transition movement help solve the NHS's problems?" Journal of Public Health 39, no. 4 (2016): 841-45.

19. Hopkins (2014), "Meet the man bringing Transition to the NHS".

20. Timothy Morton (2010). The Ecological Thought. (Cambridge, MA: Harvard University Press, 2010).

21. Charlene Spretnak (1997). The Resurgence of the Real: Body. Nature, and Place in a Hypermodern World (New York, NY: Routledge, 1997).

22. Theodore Roszak (1999). The Gendered Atom: reflections on the sexual psychology of science (Berkeley, CA: Conari Press, 1999), 97.

23. e.g. Tim Clarke (2011), The Cambridge Introduction to Literature and the Environment (2011); Garrard (2011), Ecocriticism (2011).

24. Carolyn Merchant (1980), The Death of Nature: Women, Ecology and the Scientific Revolution (New York, NY: HarperCollins, 1980); Val Plumwood (1993), Feminism and the Mastery of Nature (London: Routledge, 1993); J.K Gibson-Graham (2011), "A feminist project of belonging for the Anthropocene." Gender, Place and Culture 18, no. 01 (2011): 1-21.

25. Williams, Roberts, and McIntosh (2012) . Radical human ecology: Intercultural and indigenous approaches (Farnham: Ashgate Publishing, Ltd. 2012); Kothari et al. (2019). Pluriverse: a postdevelopment dictionary (New Delhi, Tulika Books, 2019).
26. Wade Pickren (2019). Psychology and Health: culture, place, history (London: Routledge, 2019), 104.

27. Jay Griffiths (2009), "The far-seers of art." In Julie's Bicycle (eds.), Long Horizons: an Exploration of Art and Climate Change (London: British Council), 8.

\section{BIBLIOGRAPHY}

Boaden, Ruth., Gill Harvey., Claire Moxham, and Nathan Proudlove. Quality improvement: theory and practice in healthcare: NHS Institute for Innovation and Improvement, 2008.

Cavanagh, Bliss, Kirsti Haracz, Miranda Lawry, and Carole James. "It's like another world: the perceived beneficial effects of an artistically designed multisensory environment." Medical Humanities 45, no. 1 (2019): 52-9.

Center for Disease Control and Prevention. "The Value of Systems Thinking.". https://www. youtube.com/watch?v=Fo3ndxVOZEo. Accessed May 30, 2019.

Chalquist, Craig. "A look at the Ecotherapy research evidence." Ecopsychology 1, no. 2 (2009): 64-74.

Clarke, Tim. The Cambridge Introduction to Literature and the Environment. Cambridge: CUP, 2011.

Coghlan, Andy. "Fighting climate change is opportunity to improve public health." New scientist, no. 3027 (2015). https://www.newscientist.com/article/ mg22630273-900-fighting-climate-change-isopportunity-to-improve-public-health/

Costello, Anthony, Mustafa Abbas, Adriana Allen, Sarah Ball, Sarah Bell, Richard Bellamy, Sharon Friel., et al. "Managing the health effects of climate change: Lancet and university College London Institute for global health Commission." Lancet 373, no. 9676 (2009): 1693-733

Garrard, Greg. Ecocriticism, 2nd ed. London: Routledge, 2011

Gawande, Atul. "The Century of the System." BBC Reith Lectures. BBC Radio 4, 2014. https://www. bbc.co.uk/programmes/b04sv1s5. Accessed March 30, 2019.

Gibson-Graham, J.K. "A feminist project of belonging for the Anthropocene." Gender, Place \& Culture 18, no. 1 (2011): 1-21.

Griffiths, Jay. "The far-seers of art"." In Long Horizons: an Exploration of Art and Climate Change, edited byJulie's Bicycle. London: British Council, 2009.

Hopkins, Rob. "Meet the man bringing Transition to the NHS." Transition Network, 2014. https://transitionnetwork.org/ news-and-blog/meet-the-man-bringing-transition-to-thenhs. Accessed March 30, 2019.

IPCC. "Special Report: Global Warming of $1.5^{\circ} \mathrm{C}$. .", 2018. https://www.ipcc.ch/sr15/.

Kothari, Ashish., Ariel Salleh., Arturo Escobar., Federico Demaria and Alberto Acosta. Pluriverse: a post-development dictionary. New Delhi: Tulika Books, 2019.

Lambertini, Marco., Elizabeth Maruma Mrema, and Maria Neira. "Coronavirus is a warning to us to mend our broken relationship with nature." The Guardian, 2020. Accessed August 25, 2020

Lang, Tim, and Geof Rayner. "Ecological public health: the 21 st century's big idea? an essay by TIM Lang and Geof Rayner." BMJ 345 (2012), e5466.

Lewis Williams, Rose Roberts, and Alastair McIntosh. eds. Radical Human Ecology: Intercultural and indigenous approaches. Farnham: Ashgate Publishing, Ltd, 2012

Merchant, Carolyn. The Death of Nature: Women, Ecology and the Scientific Revolution. New York, NY: HarperCollins, 1980.

Morton, Timothy. The Ecological Thought. Cambridge, MA: Harvard University Press, 2010.

One Health Global Network. "One Health. What is One Health?" http://www.onehealthglobal.net/what-is-onehealth. Accessed May 30, 2019.

Pickren, Wade. Psychology Health: culture, place, history. London: Routledge, 2019. 
Plsek, Paul E, and Trisha Greenhalgh. "The challenge of complexity in health care." BMJ 323, no. 7313 (2001): 625-8.

Plumwood, Val. Feminism and the Mastery of Nature. London: Routledge, 1993.

Roszak, Theodore. The Voice of the Earth. New York, NY: Simon \& Schuster, 1992.

The Gendered Atom: reflections on the sexual psychology of science. Berkeley, CA: Conari Press, 1999.
Smith, James N, Rob Hopkins, and David Pencheon. "Could the transition movement help solve the NHS's problems?" Journal of Public Health 39, no. 4 (2017): 841-5.

Spretnak, Charlene. The Resurgence of the Real: Body, Nature, and Place in a Hypermodern World. New York, NY: Routledge, 1997.

Townsend, Solitaire. "Making sustainability so desirable it becomes normal." Seminar at De Montfort University, 2019. Accessed April 4, 2019.
Underwood, James. "Doctors against climate catastrophe." The Guardian, Letters, 2019. Accessed June 27, 2019.

Watts, Nick, W Neil Adger, Paolo Agnolucci, Jason Blackstock, Peter Byass, Wenjia Cai, Sarah Chaytor., et al. "Health and climate change: policy responses to protect public health." The Lancet 386, no. 10006 (2015): 1861-914. 